\title{
Pedagogy and Cultural Manifestations in the Weaving Practices of the Yakan Tribe
}

\author{
Espiridion D. Atilano Jr. \\ Ateneo de Zamboanga University, Zamboanga City, Philippines \\ Email: espieatilano@gmail.com
}

Received July 2014

\section{Abstract}

The Yakan weaving practices were integral to the personal and cultural life of the tribe. This study sought to describe how the teaching and learning happen in the Yakan weaving practices as well as determine the significance of weaving in the economic, social and environmental aspects of the Yakans' way of life. Anchored on the Social Cognitive Theory (SCT) of Albert Bandura, learning occurs through the observation and imitation of the innate person (learner) of the modeled behavior (weaving) in a learning environment (Socio-cultural norms in the Yakan community.) The study utilized a qualitative and descriptive design. Pertinent data were obtained through Focus Group Discussion (FGD), Key Informant Interview (KII) and Fieldwork Observation Checklist (FOC). The respondents of the FGD were the weavers of the two Yakan communities in the cities of Zamboanga and Lamitan. The communities also served as the subject of the FOC. Three experts on Yakan textile and culture were probed in the KII. Purposive Sampling Technique was used to select the respondents of the FGD and the Snowball method to identify the informants for the KII. Results show that the Yakan weaving practices are transferred from one generation to another by the mothers to their daughters. The pedagogy could either be structured, through demonstration and modeling by the teacher or informal through observation and imitation of the learner. Moreover, the interplay of culture is evident in the Yakan weaving through the economic and social practices as well as the adaptation in the environmental changes of the tribe. Lastly, there is a need to enhance the teaching and learning of weaving to accommodate more learners and to strike a balance between the preservation of the tribe's culture and the profitability of the weaving textile business.

\section{Keywords}

Weaving, Pedagogy, Cultural Manifestation, Social Cognitive Theory, Yakan Tribe

\section{Background of the Study}

The Yakan is one of the ethno-linguistic tribes found in southern Philippines. Originally they were considered as the dominant inhabitants of Basilan Province. However, at the height of the conflict between the armed forces of the government and the Moro National Liberation Front (MNLF) in the 1970's, a number of Yakan residents from Basilan were forced to evacuate the conflict-ridden area. Some of them stayed in the town of Lamitan 
while the others managed to settle in Zamboanga City. According to Wee (2006) [1], as new migrants of the place, the Yakan had no means of livelihood to sustain their daily needs. To survive the odds, according to Pasilan (2012) [2], the women of the tribe took up their looms and began to weave again. Aside from making both ends meet for the family, the Yakan weaving became a means to promote the cultural heritage of the tribe. Thus, the traditional backloom strap weaving was revived.

Weaving is one of the definitive features of the Yakans. The Yakan weaving is known for the intricacy of its designs, the eye-catching and colorful textiles with tiny motifs used in the woven clothes and garbs. This craft which has been passed on to generations has undergone changes in its place in society and culture particularly in terms of designs, materials and procedures used.

The Yakan weaving is an indigenous local treasure, through which the tribe earned high regard for their local craft. Barbosa (2004) [3] said, "The Yakan textile is a product that speaks of their culture and tradition and it was one of the earliest items that reached neighboring nations." Moreover, to understand how the craft evolved, there is a need to trace the manner how the weaving practices are transferred from one generation to another.

The teaching and the learning of Yakan weaving play an important role in the preservation of the craft. The manner of transferring the skills and practices of weaving is crucial to the tribe because partly the weaving tradition is integrated in the social and cultural identity of the Yakans. Anchored on the social cognitive theory of Bandura (1977) [4] which states that behavior is learned from the environment through the process of observational learning, the learners pay attention to the people they see in their immediate environment (models) and encode their behavior and at a later time they may imitate the behavior they have observed. Learning comes from each member of the community both from the observation of the other members and experiences of this tradition. Further, the pedagogy of weaving involves certain factors such as relevance and reward influencing the imitation of the learner. According to Bandura (1977) [4], the child observes someone being rewarded for a particular behavior and this affects the child in the same way as it would have the child produced the behavior herself and has been rewarded for it. In the Yakan weaving practices, the reward which serves as the motivation to the learner to be familiar with the craft is the affirmation given by the teacher (older weaver) and the recognition provided by the community as well as the money generated by the older weaver every time she finishes and sells a woven item. Hence, the pedagogy or the teaching and learning process of the Yakan weaving is seen as a social recognition and a source of income which makes the weaving practices a medium of preserving the culture and tradition of the tribe.

In the realm of economics, weaving has served as a means of earning a living for the survival of the tribe. The promotion of the craft is showcased in trade fairs and other weavers' expo at least seven times a year to further endorse the Yakan cloth abroad. Moreover in the realm of the art and style of weaving, according to Wee (2006) [1], contacts with Christian Filipinos and the American Peace Corps brought about several changes in the weaving practices, such as many weavers resorted to the convenience of chemical dyes and they started weaving table runners, placemats, wall decors, purses and other items which were not seen or visible in a traditional Yakan house. This means that the Yakans have learned to adapt to the socio-cultural and economic changes of their external environment for purposes of profit gains.

These could be various reasons or factors that may explain the gradual change in the Yakan society and culture, one of which is socialization and cultural adaptation which includes cultural borrowing from their immediate external environment. Another reason as stated by Pasilan (2012) [2] is the influx of modern technology and gadgets such as cellular phones and the internet, which facilitated better communication with the rest of the world, where culture has influenced the younger generations of the Yakan tribe. In spite of all these changes and advances in their environment, Salang (2012) [5] generalized that Yakan weaving has survived despite the threats on its existence because it is an important source of income in the Yakan tribe.

This study was conducted to determine how the Yakan weaving is passed on from one generation to the next. Moreover, it sought to identify the factors that have significance in the economic and social life of the tribe. Further, given the socio-cultural changes that are taking place, this study sought to validate whether there are modifications in the weaving practices of the Yakans as brought about by the changes in their environment.

\section{Statement of the Problem}

This study aimed to describe the pedagogy of the Yakan weaving practices. It sought to identify the cultural relevance embedded in the practice of the craft and to establish how the weaving culture was preserved. It also 
sought to determine the significance of weaving in the economic, social and environmental aspects of the Yakans' way of life. Specifically it sought to answer the following questions:

1) How does the teaching and learning happen in the Yakan weaving practice?

2) How does the teaching and learning of weaving interplay with the cultural life of the Yakans in terms of: Economic livelihood, Social identity, and Environmental adaptation?

\section{Hypothesis}

This study hypothesized that,

Ho1: The teaching and learning of the Yakan weaving is done through demonstration and modeling of the teacher and the observation and imitation of the learner.

Ho2: There is interplay between the weaving practices and the cultural life of the Yakans particularly on the economic, social and environmental aspects.

\section{Theoretical Framework}

This study is anchored on the Social Cognitive Theory (SCT) of Albert Bandura. Figure 1 shows that learning occurs through the observation and imitation of the innate person (learner) of the modeled behavior (weaving). Moreover, the learning environment (socio-cultural norms in the Yakan community) serves as determinants in the acquisition of weaving skills (Bandura, 1986) [6].

\section{Conceptual Framework}

As shown in Figure 2, there is an assumption that there exist multiple cultural manifestations in the aspects of economic, social and environmental in the learning process of the Yakan weaving. These manifestations may affect or influence the weaving practices of the Yakans.

\section{Methods}

The study made use of qualitative and descriptive research designs because it sought to illustrate the pedagogy

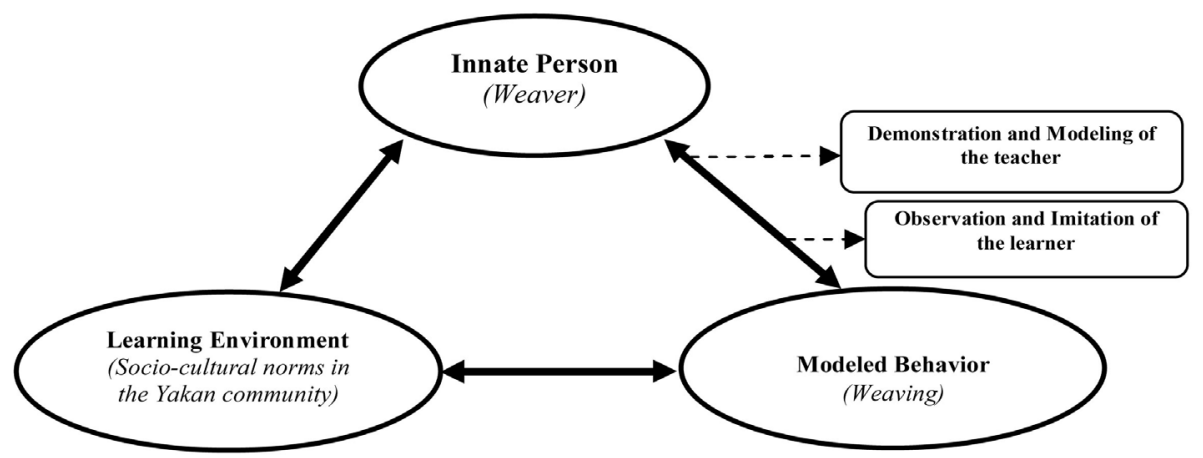

Figure 1. Modified social cognitive theory in the yakan weaving (Bandura, 1986) [6].

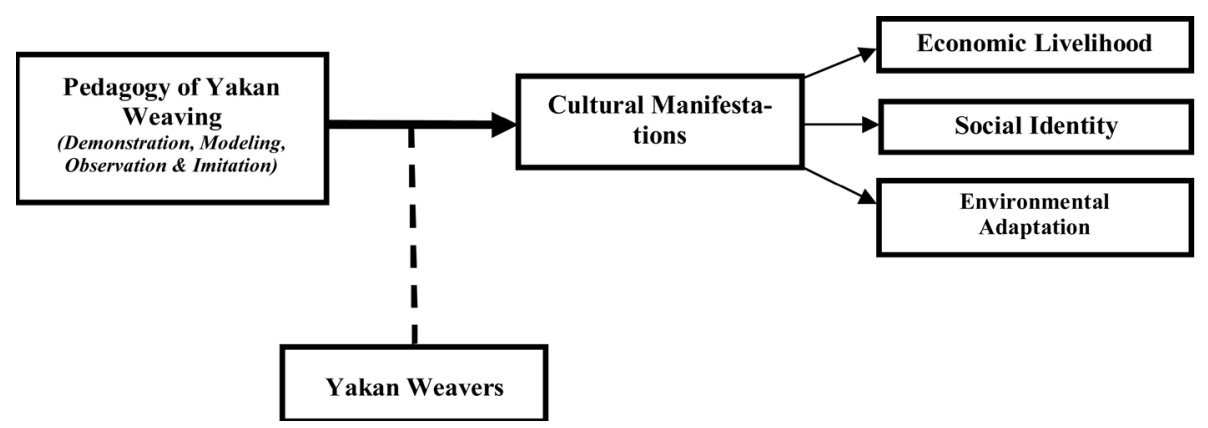

Figure 2. Conceptual framework of the study. 
involved in the Yakan weaving practices. More so, it aimed to identify the socio-cultural, economic and environmental significance of the craft. Further, the study utilized qualitative method in which the researcher described the way the tribe handed down the weaving practices from one generation to the next. Also, it aimed to describe the cultural manifestations of the craft based on the data gathered, and based on the in-depth analyses of the responses of the informants and participants to the guide questions of the Focus Group Discussion and Key Informant Interview.

The locales of the study were the Yakan village in Zamboanga City and the Yakan community in Lamitan City. Pertinent data were gathered through Focus Group Discussion (FGD), Key Informant Interview (KII) and the Fieldwork Observation Checklist (FOC). There were six respondents for the FGD per Yakan community and three informants for the KII. The respondents of the FGD were selected utilizing the Purposive Sampling Technique and the Snowball method in identifying the informants for the KII.

\section{Results}

Results show that the Yakan weaving practices were taught or transferred from one generation to another by either the grandmothers to their granddaughters or mothers to their daughters. The pedagogy could either be structured, through demonstration and modelling or informal through imitation and observation from the learnerchild. Moreover, the interplay of culture was evident in the Yakan weaving through the economic livelihood, social identity and environmental adaptation of the tribe.

The weaving is taught through the teacher (mother/grandmother/relative/other weaver) demonstrating a step by step procedure from (maghani) warping or counting of threads, (magpenne) designing of patterns to the actual (magtennun) weaving. This was affirmed by all of the respondents. Additional responses include the learner mimicking the mother's weaving structure and design while at the same time memorizing and observing the process. Moreover, it was mentioned by the respondents that the older weaver models to the learner the process of weaving.

The data gathered from the Fieldwork Observation Checklist (FOC) were analyzed by tracing the teaching and learning process of weaving by the Yakans. The researcher carefully scrutinized the field notes and other related documents such as pictures and consolidated the information gathered to summarize the findings.

As seen in Table 1, both communities have adapted to societal changes in terms of material culture,. This was evident with the modern clothing they wore as alternative to their traditional costumes and garbs. Moreover, the communities were slightly urbanized, especially the community located at the town proper of Lamitan City. Nevertheless, the Yakans in both communities maintained the weaving area in the terrace of their houses equipped with the weaving materials ranging from backstrap loom to the different colorful threads.

In addition, the results revealed that the Yakan weaving center in Zamboanga City was more inclined in the selling of their woven products and this was done through the cooperative. They supplied in wholesale to other cities like Manila and Davao. They also sold the woven items in retail through the small stores in the community. Aside from actively engaging in the selling of woven products, the other members of the tribe were integrated in the economic operations of the city. In particular, the Yakan men were working in companies and business enterprises in the town proper. This kind of economic participation was brought about by the need to earn a living.

The results in Table 1 further validate how the Yakans learn the craft of weaving depends on the learning environment, because knowledge is not formed in a separate process that exists somehow in social isolation. This is further validated by the words of Pasilan (2012) [2] that the Yakan environment determines the nature of their textile production and the evolution of what they traditionally wore has mirrored the social and environmental changes that took place in their society.

The textile production is inherent in a Yakan environment. It has a great impact on the learning processes of the weavers, particularly because the processes of weaving from warping, designing to the actual weaving are not taken for granted because more than the cultural value and social identity it represents, it is also seen as an option to generate income for the family. The weaving materials are found immediately in the community; looms in almost every house and outside are hundred of ready-to-sell woven items fill the community shops of the Yakan village in Zamboanga City. The manner of producing the woven items by the Yakans is part of the identity of the people and is linked to a number of inter-related factors, such as the physical environment and culture.

Moreover, the FGD results suggest that the learning of weaving is integrated in the tribe's daily life. The 
Table 1. Summary of the fieldwork observation checklist.

\begin{tabular}{|c|c|c|}
\hline Themes & Yakan Village (Zamboanga City) & Yakan Community (Lamitan City) \\
\hline $\begin{array}{l}\text { Natural } \\
\text { Settings }\end{array}$ & $\begin{array}{l}\text { - Situated in a highland village in Upper Calarian. A small } \\
\text { area fronting the sea. }\end{array}$ & $\begin{array}{l}\text { - The entire city is inhabited mostly by Yakans. } \\
\text { - The finest weavers are situated upland. }\end{array}$ \\
\hline $\begin{array}{l}\text { Material } \\
\text { Culture }\end{array}$ & $\begin{array}{l}\text { - } \quad \text { Houses are made of contemporary materials. } \\
\text { - } \quad \text { The inhabitants of the village are wearing modern clothes. } \\
\text { - The area for weaving is beside the community shops. }\end{array}$ & $\begin{array}{l}\text { - } \quad \text { Yakans are wearing modern clothes. } \\
\text { - The community is slightly urbanized. } \\
\text { The terrace used for weaving is part of the } \\
\text { structure of the house }\end{array}$ \\
\hline $\begin{array}{l}\text { Economic } \\
\text { Livelihood }\end{array}$ & $\begin{array}{l}\text { - Wholesalers and retailers of their woven products } \\
\text { through the cooperative. } \\
\text { Most of them are integrated in the economic operations } \\
\text { of the city. }\end{array}$ & $\begin{array}{l}\text { - } \quad \text { Some are still cultivators/farmers } \\
\text { - } \quad \text { Owners of micro businesses (small stores) } \\
\text { - } \quad \text { Urbanized living } \\
\text { - } \text { Involvement in the Yakan Women } \\
\text { Cooperative }\end{array}$ \\
\hline $\begin{array}{l}\text { Weaving } \\
\text { Practice }\end{array}$ & $\begin{array}{l}\text { - A series of small stores filled with Yakan woven items } \\
\text { ranging from bags, cloth, table runners to cellular phone } \\
\text { holders) are found in the village. } \\
\text { - There are roughly } 20 \text { weavers in the village. } \\
\text { - } \quad \text { A specific area in the village allocated for weaving purposes. }\end{array}$ & $\begin{array}{l}\text { - The presence of the Gilingan (spinning wheel) } \\
\text { in selected houses. } \\
\text { - Weavers are situated in the hinterland area of } \\
\text { the city although a number of them are found } \\
\text { downtown. } \\
\text { - Less number of weavers doing the actual } \\
\text { weaving in their respective houses. }\end{array}$ \\
\hline
\end{tabular}

Yakans are identified as weavers; it is part of their ethnic background. The knowledge on weaving has been transferred from one generation to another which provides the tribe with a special historical legacy. There is an obvious interaction between the learning and teaching generations among the Yakans. The teaching method used in the Yakan weaving practice is "learning by doing". The learners acquire the skills from their own experiences. The warping and designing are learned by practising and so is the weaving, but under the guidance of an experienced weaver. In the area of environmental adaptation, all the respondents from the Yakan village in Zamboanga City emphasized how they adapted the weaving practices to the various cultural changes in society. They started using the commercialized substitute of weaving materials such as mercerized cotton and colored threads instead of the abaca and pineapple fibers used as threads as well as tree barks used as dyes. Moreover, the results suggest that the present weaving community is utilizing modern techniques into acquiring the original designs of the costume and other woven textiles. These Yakans maintained the traditional forms and styles despite replacing the handwoven fabric with imported cotton cloth and other techniques.

\section{Conclusion}

Based on the findings of the study the following conclusions can be drawn: hypothesis 1 which stated that the teaching and learning of the Yakan weaving is done through demonstration and modeling of the teacher and the observation and imitation of the learner is accepted. Furthermore, hypothesis 2 which stated that there is interplay between the weaving practices and the cultural life of the Yakans particularly on the economic, social and environmental aspects is also accepted. The two hypotheses were accepted because the pedagogy could either be structured, through demonstration and modelling or informal through imitation and observation from the learner-child. Moreover, the interplay of culture is evident in the Yakan weaving through the economic livelihood, social identity and environmental adaptation of the tribe.

First, the teaching-learning practices in the art of Yakan weaving have passed through the following approaches or processes that include demonstration and modelling facilitated by an older weaver and observation and imitation from the perspective of the learner without having a formal instruction. These are supported by the social cognitive theory of Bandura that stipulated that imitation, modelling and observation are ways whereby an individual can learn any craft of skills. Moreover, Bandura (1977) [4] states that behavior is learned from the environment through the process of observational learning, the learners pay attention to the people they see in their immediate environment (models) and encode their behavior. At a later time they may imitate the behavior they have observed.

Second, the teaching and learning of weaving interplays with the cultural life of the Yakans through the following aspects: economic, social and cultural. In the realm of economic, the weaving practice serves as a form 
of livelihood since weaving is not solely confined for the consumption purpose of the community, rather for commercial and profit gains as well. More so, in the area of socio-cultural, the weaving craft serves various purposes in the Yakan society. First, the designs function as a determinant of the weavers' social status or social identity. Second, the process of weaving from warping, designing to the actual weaving if achieved by a single weaver, translates to social recognition. It becomes a status symbol among the Yakan weavers.

Lastly, the weaving practices have adapted to the various environmental changes brought about by modernity and advancements in technology. Moreover, the scarcity of raw materials such as abaca fibers and tree barks used in weaving in the past, have led to the extensive use of commercialized alternatives that are readily available in the market.

\section{References}

[1] Wee, D. (2006) Yakan Cloth, Now a Pride of Zamboanga.

http://zamboangajournal.blogspot.com/2006/01/yakan-cloth-now-pride-of zamboanga.html

[2] Pasilan, E. (2012) The Yakans of Lamitan, Basilan and the Evolution of Their Traditional Costumes. Anthropological Association of the Philippines, Quezon City. Journal of the Ugnayang Pang-Aghamtao, Inc.

[3] Barbosa, A. (2004) Yakan Textile: An Ethnographic Perspective. Institute of Culture for Western Mindanao, Zamboanga City.

[4] Bandura, A. (1977) Self-Efficacy: Toward a Unifying Theory of Behavioral Change. Psychological Review, 84, 191215. http://dx.doi.org/10.1037/0033-295X.84.2.191

[5] Salang, B. (2012) The Role of Women in the Yakan Weaving the Maintenance and Preservation of Cultural Heritage. International Association of Multidisciplinary Research.

[6] Bandura, A. (1986) Social Foundations of Thought and Action: A Social-Cognitive Theory. Prentice Hall, Englewood Cliffs, NJ. 